\section{Expert Opinion}

1. Introduction

2. LH-RH antagonists versus agonists

3. LH-RH antagonists

4. $\mathrm{LH}-\mathrm{RH}$ antagonists for in vitro fertilization

5. LH-RH antagonists in tumor therapy

6. Cetrorelix (CET)

7. Abarelix

8. Ganirelix

9. LH-RH antagonists: new candidates for clinical applications

10. Orally active non-peptidic antagonists of LH-RH receptors

11. Expert opinion

\title{
Luteinizing hormone-releasing hormone antagonists
}

\author{
Gábor $\mathrm{Mezo}^{\dagger} \&$ Marilena Manea \\ ${ }^{\dagger}$ Eötvös Loránd University, Hungarian Academy of Sciences, Research Group of Peptide Chemistry, \\ 1117 Budapest, Pázmány P. stny. 1/A, Hungary
}

Background: Luteinizing hormone-releasing hormone (LH-RH) plays a central role in the vertebrate reproduction by regulating gonadal activity. Based on its binding to pituitary $\mathrm{LH}-\mathrm{RH}$ receptors, as well as to $\mathrm{LH}-\mathrm{RH}$ receptors expressed on cancer cells, LH-RH agonists and antagonists have been developed for different therapeutic applications. Objective/method: Here we give an overview of the most relevant LH-RH antagonists and their therapeutic applications. Recently patented compounds as well as drug formulations and dosage are presented. Conclusion: LH-RH antagonists have found clinical applications in in vitro fertilization, benign prostatic hyperplasia, endometriosis and in the treatment of hormone-dependent tumors. Work in progress is focused on further development of both peptidic and orally active non-peptidic LH-RH antagonists.

Keywords: gonadotropin-releasing hormone, hormone-dependent tưmors, in vitro fertilization, luteinizing hormone-releasing hormone, $\mathrm{LH}-\mathrm{RH}$ antagonists, non-peptidial $\mathrm{LH}-\mathrm{RH}$ antagonists, tumor therapy

\section{Expert Opin. Ther. Patents (2009) 19(12):1771-1785}

\section{Introduction}

The hypothalamic decapeptide luteinizing hormone-releasing hormone (LH-RH; Glp-His-Trp-Ser-Tyr-Gly-Leu-Arg-Pro-Gly- $\mathrm{NH}_{2}$ ), also called gonadotropin-releasing hormone (GnRH), was discovered in 1971 by Andrew V. Schally and his colleagues [1]. (Schally's group was the first to accomplish its isolation, elucidation of structure and synthesis.) The primary biological function of LH-RH is the regulation of the gonadal activity by releasing gonadotropic hormones, luteinizing hormone $(\mathrm{LH})$ and follicle stimulating hormone (FSH), from the anterior pituitary gland, that act on the female and male gonads to trigger the gametogenesis, as well as the synthesis and release of sex-steroids. Therefore, this neurohormone plays a central role in vertebrate reproduction [2]. LH-RH is secreted in a pulsatile fashion by the hypothalamic neurons [3] and it has a short half-life in vivo of $2-5 \mathrm{~min}$ [4]. Continuous exposure to LH-RH results in the suppression of gonadotropin and sex-steroid secretion due to the desensitization of gonadotropic cells and the downregulation of pituitary LH-RH receptors (LH-RH-Rs) [5]. The observed chemical castration is a medical approach to therapy of hormone-dependent tumors such as prostate and breast tumors, benign prostatic hyperplasia, endometriosis and female infertility [6]. Since the discovery of LH-RH, 23 natural isoforms have been identified [7], several thousand synthetic agonists and antagonists have been developed and some of them have found therapeutic applications (e.g., buserelin, goserelin, triptorelin and leuprolide as superagonists; cetrorelix, abarelix and ganirelix as antagonists) [8].

\section{LH-RH antagonists versus agonists}

By modifying the Gly ${ }^{6}$ and $\mathrm{Gly}^{10}$ in mammalian LH-RH (LH-RH-I), superagonist derivatives can be produced. Gly ${ }^{6}$ is replaced by $\mathrm{D}$-amino acid derivatives with bulky 

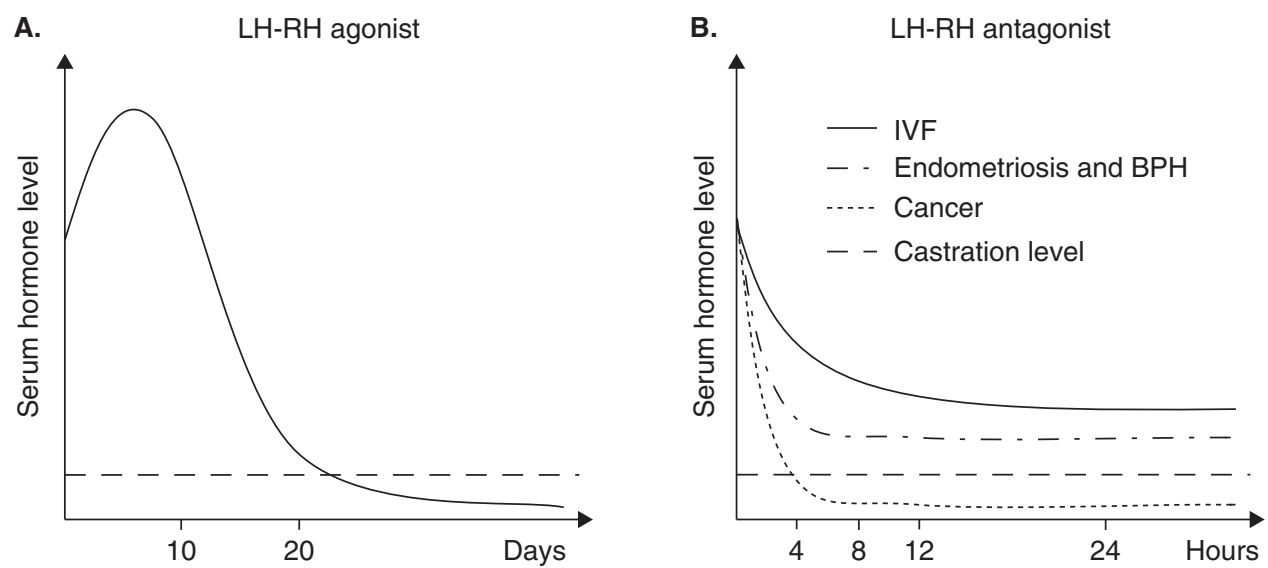

Figure 1. Effect of LH-RH agonists (A) and antagonists (B) on serum hormone levels (e.g., LH, FSH, testosterone, estradiol levels).

BPH: Benign prostatic hyperplasia; IVF: In vitro fertilization; LH-RH: Luteinizing hormone-releasing hormone.

apolaric side chain (Leu, Trp, $\operatorname{Ser}\left({ }^{\mathrm{t}} \mathrm{Bu}\right)$, His $\left.(\mathrm{Bzl})\right)$, while Pro ${ }^{9}-$ Gly ${ }^{10}-\mathrm{NH}_{2}$ is modified as Pro-NHEt or Pro-Azgly- $\mathrm{NH}_{2}$ [9]. Compared to the natural LH-RH, five or more substitutions of the amino acids in positions $1-3,6,10,(5,8)$ are required for the preparation of antagonists [10].

The main difference between LH-RH antagonists and agonists is represented by their mode of action on the release of gonadotropins. After an initial stimulatory effect, the agonists lead to the desensitization of gonadotropic cells and to a decrease in the number of LH-RH-R on the cell membrane (downregulation), followed by the reduction of $\mathrm{LH}$ and FSH release $[10,11]$. The blockade of the production of gonadotropins results in the inhibition of sex-steroid production. The complete inhibition can be reached in $15-20$ days, causing a subsequent delay in the therapeutic benefit (Figure 1A) [12]. The temporary increase of sex-steroids (e.g., testosterone surge) can exacerbate the hormone-sensitive cancers and may cause catastrophic flare events such as spinal-cord compression and urinary-tract obstruction. This clinical flare should be avoided especially in the case of cancer metastasis [13]. The application of LH-RH antagonists results in an immediate decrease of LH and FSH levels by a rapid, but reversible blockade of LH-RH-Rs without any flare (Figure 1B). However, many of the first and second generation antagonists showed anaphylactic reactions due to the histamine release, which prevented their application in clinical trials [10,14]. This side effect was greatly reduced in the third generation LH-RH antagonists (e.g., cetrorelix, ganirelix). Some of these antagonists are currently on the market and others are in clinical trials.

\section{LH-RH antagonists}

The most promising third and fourth generation LH-RH antagonists contain Ac-D-Nal-D-Cpa-D-Pal in the $N$-terminal part and D-Ala in position 10. In positions 5, 6 and 8, a large variety of amino acid derivatives have been substituted (Figure 2). At present, cetrorelix (Æterna Zentaris), abarelix (Preacis) and ganirelix (Organon, Inc.) are on the market, while antarelix/teverelix (Ardana), degarelix (Ferring Pharmaceutical), ozarelix (Æterna Zentaris), ornirelix (Oakwood Laboratories), iturelix (Ares Serono), azaline B and acyline (NICHD/Salk Institute) are in clinical trials (Table 1) [15-26].

The main areas where LH-RH antagonists are or could be recommended are the in vitro fertilization (IVF), benign prostatic hyperplasia $(\mathrm{BPH})$, endometriosis and cancer therapy [10,26-28]. The administration of LH-RH antagonists leads to a reduction of serum hormone levels in a dose-dependent manner. Since the hormone level required for various therapeutic applications is different (Figure 1B), the dose of LHRH antagonists must be carefully chosen. In the case of IVF, the complete hormonal withdrawal should be avoided, while chemical castration is needed for efficient tumor therapy. The attainment of a low, but not completely reduced hormone level in BPH and endometriosis is also recommended [12]. Some of the LH-RH antagonists such as cetrorelix and ganirelix are efficient in IVF and employed for assisted reproduction technology (ART) treatment [11]. However, abarelix is not suitable for this application, but it is effective in tumor therapy [29]. At present, abarelix is the only LH-RH antagonist clinically used as an antineoplastic agent. The studies with cetrorelix indicate that the dosage of the LH$\mathrm{RH}$ antagonist might influence the therapeutic application [12]. A low dose for IVF (clinical application) [11,12], a medium dose for BPH (Phase III clinical trial) [12,29] and a high dose for the prostate cancer treatment (Phase I clinical trial) are necessary [12]. However, the high dose might cause unwanted side effects due to the fact that cetrorelix has higher histaminereleasing properties than other LH-RH antagonists such as abarelix, ganirelix and degarelix [30]. Therefore, in addition to new compounds (e.g., degarelix [31], ozarelix [32], non-peptidic antagonists [33]), most of the recent patents are focused on the 


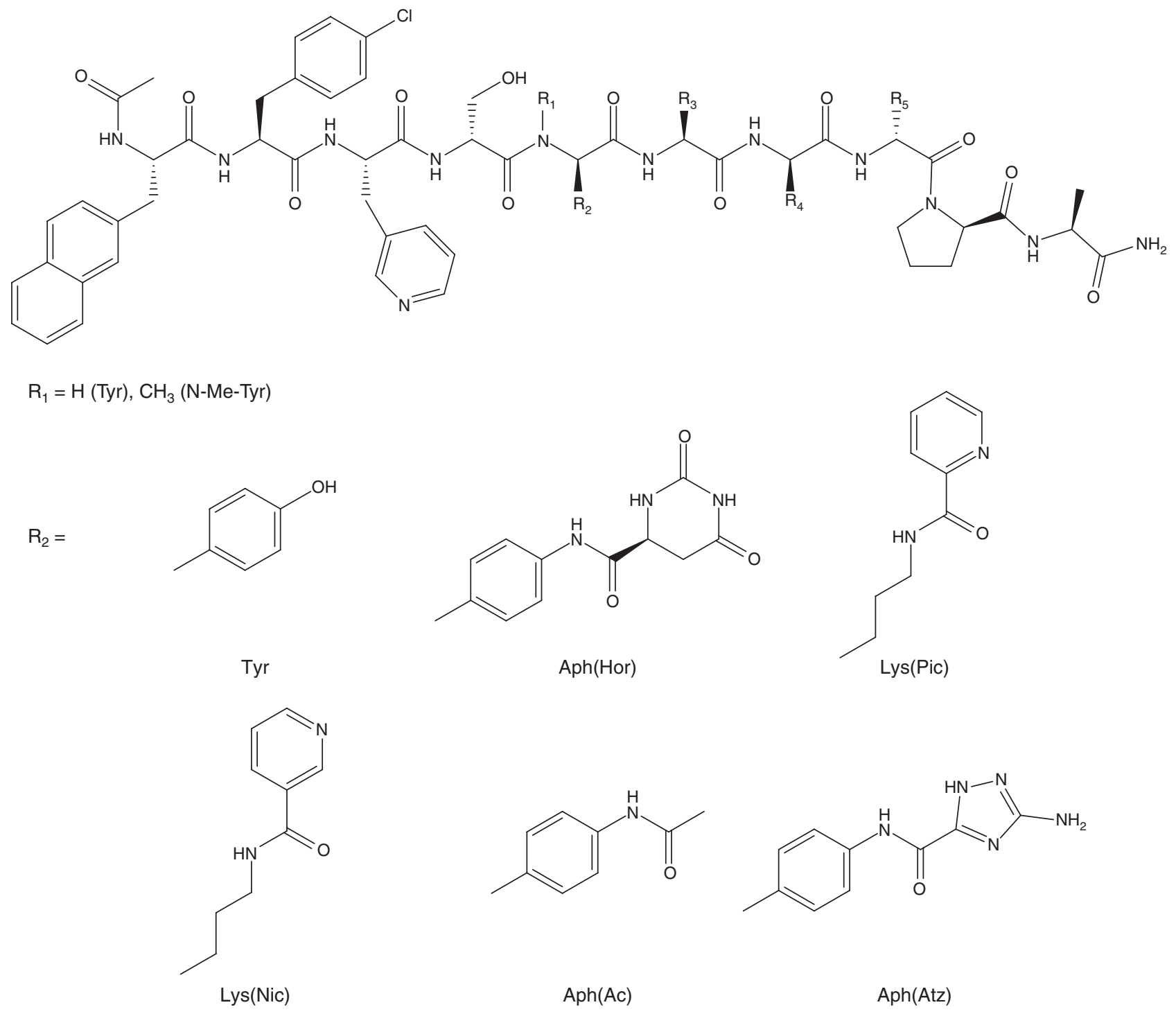

Figure 2. Chemical structures of LH-RH antagonists.

6Anic: 6-Aminonicotinoyl; Aph: 4-Aminophenylalanine; Atz: 5'-(3'-Amino-1H-1',2',4'-triazolyl); Cit: Citruline; Cba: Carbamoyl; Cpa: 4-Chlorophenylalanine; Et: Ethyl; hArg: Homoarginine; hCit: Homocitruline; Hor: L-Hydroorotyl; iPr: Isopropyl; LH-RH: Luteinizing hormone-releasing hormone; Nal: 2-Naphtylalanine; Nic: Nicotinoyl; Nle: Norleucine; Pal: 3-Pyridylalanine; Pic: Picoloyl.

development of drug formulations [34,35], dosage [36] and a more convenient route of administration [37,38].

\section{LH-RH antagonists for in vitro fertilization}

The in vitro fertilization process involves controlled ovarian stimulation (COS) to stimulate the follicular growth. In fact, high LH levels have a negative role in the IVF; therefore, the reduction of bioactive $\mathrm{LH}$ in the blood is required [11]. Nowadays, gonadotropins are administered in order to induce multiple follicular development, whereas LH-RH analogs are used for the prevention of premature $\mathrm{LH}$ surges in the IVF [10]. Without the application of LH-RH analogs, LH surges occur in $\sim 20 \%$ of the stimulated IVF patients [39,40]. Both LH-RH agonists and antagonists are used in ovarian stimulation for IVF. Due to their different mechanisms of action, the antagonists have several advantages in comparison with the agonists [10,41]. In contrast to LH-RH agonists, the increase of the premature $\mathrm{LH}$ can be prevented easier and faster by antagonists (within a few hours instead of 7 - 10 days). No hot flushes in patients are observed during the administration of LH-RH antagonists and the duration of ovarian stimulation protocols is shortened. However, in the meta-analysis of Phase III randomized comparative trials with LH-RH analogs, the induction of clinical pregnancy was about 3.3\% higher in the case of LH-RH agonists [42,43]. Considering these data, there is a general resistance in the clinic to further explore the use of LH-RH antagonists. 
<smiles>[B][Na]</smiles>

Cit<smiles>CCCNC(=O)c1cnccc1N</smiles>

Orn(6Anic)<smiles>CC(N)=O</smiles>

Asn<smiles>CCCCNC(=O)c1cccnc1</smiles>

Lys(Nic)<smiles>CCCCC</smiles>

$\mathrm{Nle}$<smiles>CC(=O)Nc1ccc(C)cc1</smiles><smiles>Cc1ccc(NC(=O)c2nc(N)n[nH]2)cc1</smiles>

$\operatorname{Aph}(A c)$

Aph(Atz)

$\mathrm{R}_{4}=$<smiles>CCC(C)C</smiles>

Leu

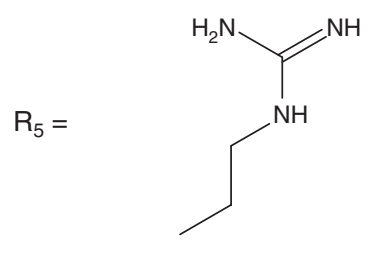

Arg

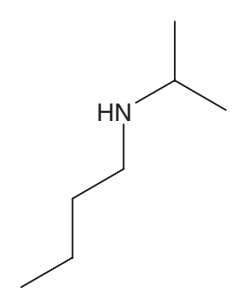

Lys(iPr)<smiles>Cc1ccc(NC(N)=O)cc1</smiles><smiles>CCCCNC(N)=O</smiles>

hCit 
Table 1. Chemical structures of clinically used third and fourth generation LH-RH antagonists.

\begin{tabular}{|c|c|}
\hline Compound & Amino-acid sequence \\
\hline Cetrorelix & Ac-D-Nal-D-Cpa-D-Pal-Ser-Tyr-D-Cit-Leu-Arg-Pro-D-Ala-NH 2 \\
\hline Abarelix & Ac-D-Nal-D-Cpa-D-Pal-Ser-N-MeTyr-D-Asn-Leu-Lys(iPr)-Pro-D-Ala-NH 2 \\
\hline Ganirelix & Ac-D-Nal-D-Cpa-D-Pal-Ser-Tyr-D-hArg(Et) ${ }_{2}$-Leu-hArg(Et) ${ }_{2}$-Pro-D-Ala-NH ${ }_{2}$ \\
\hline Degarelix & Ac-D-Nal-D-Cpa-D-Pal-Ser-Aph(Hor)-D-Aph(Cba)-Leu-Lys(iPr)-Pro-D-Ala-NH ${ }_{2}$ \\
\hline Teverelix* & Ac-D-Nal-D-Cpa-D-Pal-Ser-Tyr-D-hCit-Leu-Lys(iPr)-Pro-D-Ala-NH 2 \\
\hline Ozarelix & Ac-D-Nal-D-Cpa-D-Pal-Ser-N-MeTyr-D-hCit-Nle-Arg-Pro-D-Ala-NH2 \\
\hline Ornirelix & Ac-D-Nal-D-Cpa-D-Pal-Ser-Lys(Pic)-D-Orn(6Anic)-Leu-Lys(iPr)-Pro-D-Ala-NH 2 \\
\hline Iturelix ${ }^{\S}$ & Ac-D-Nal-D-Cpa-D-Pal-Ser-Lys(Nic)-D-Lys(Nic)-Leu-Lys(iPr)-Pro-D-Ala-NH 2 \\
\hline Acyline & Ac-D-Nal-D-Cpa-D-Pal-Ser-Aph(Ac)-D-Aph(Ac)-Leu-Lys(iPr)-Pro-D-Ala-NH 2 \\
\hline Azaline B & Ac-D-Nal-D-Cpa-D-Pal-Ser-Aph(Atz)-D-Aph(Atz)-Leu-Lys(iPr)-Pro-D-Ala-NH 2 \\
\hline \multicolumn{2}{|c|}{$\begin{array}{l}\text { *Antarelix. } \\
\text { "Orntide. } \\
\text { `Antide or Nal-Lys. } \\
6 \text { Anic: 6-Aminonicotinoyl; Aph: 4-Aminophenylalanine; Atz: 5'-(3'-Amino-1H-1',2',4'-triazolyl); Cit: Citruline; Cba: Carbamoyl; Cpa: 4-Chlorophenylalanine; } \\
\text { Et: Ethyl; hArg: Homoarginine; hCit: Homocitruline; Hor: L-Hydroorotyl; iPr: Isopropyl; LH-RH: Luteinizing hormone-releasing hormone; Nal: 2-Naphtylalanine; } \\
\text { Nic: Nicotinoyl; Nle: Norleucine; Pal: 3-Pyridylalanine; Pic: Picoloyl. }\end{array}$} \\
\hline
\end{tabular}

secretion. Due to the immediate suppression of the gonadal steroids secretion by LH-RH antagonists, they might be better candidates for hormonal tumor therapy than LH-RH agonists [46]. Second, the tumor growth can be inhibited by LHRH derivatives acting directly on the LH-RH-Rs expressed on many types of tumors [47,48] (ligand-receptor interactions induce intracellular signaling pathways). The signal transduction mechanisms mediated by LH-RH-R on tumor cells differ from the classical LH-RH-R signals known to operate in the pituitary [49,50]. In the pituitary gland, LH-RH-IRs are positively coupled to heterotrimeric $\mathrm{G}_{\mathrm{q} / 11}$ proteins that activate the phospholipase $\mathrm{C}$, with consequent $\mathrm{Ca}^{2+}$ mobilization and activation of protein kinase $\mathrm{C}$ isozymes [51,52]. In cancer cells, LH-RH-IR couples to multiple G proteins, and the antiproliferative signal transduction is mainly mediated through $G$ protein $\alpha_{i}[53,54]$. On LH-RH-R positive cancer cells, most of the LH-RH antagonists induce a time- and dose-dependent inhibition of proliferation indicating that LH-RH antagonists might act like agonists in tumor cells.

Besides LH-RH-IRs, the presence of an additional receptor (probably a functional receptor that recognizes LH-RH-II (Glp-His-Trp-Ser-His-Gly-Trp-Tyr-Pro-Gly- $\mathrm{NH}_{2}$ ) or a splice variant of LH-RH-IIR) was indicated in several types of tumor cells. After the knockout of LH-RH-IR in endometrial and ovarian cancer cells, the antiproliferative effect of LH-RH agonist triptorelin was abrogated, while the growth-inhibitory effect of LH-RH antagonist cetrorelix and LH-RH-II persisted [55]. Therefore, LH-RH-II antagonist peptides (Ac-DNal-D-Cpa-D-Pal-Ser-His-D-Lys-Trp-Tyr-Pro-D-Ala-NH ${ }_{2}$, Ac-D-Nal-D-Cpa-D-Pal-Ser-His-D-Lys-Trp-Leu-Pro-D-Ala$\mathrm{NH}_{2}$ ) that have antitumor activity in vivo without side effects might be good candidates for tumor therapy [56]. The synergism of indirect and direct antitumor activity of LH-RH derivatives on hormone-dependent tumors has not been studied in detail yet. However, in the case of steroid hormone-independent tumors LH-RH agonists and antagonists potentially act only directly via tumor LH-RH-Rs.

Based on their binding to receptors, LH-RH derivatives can also be used in targeted tumor therapy. The hormone peptides are employed as targeting moieties to which cytotoxic drugs are attached. Currently, only one LH-RH derivative-drug conjugate developed in Schally's group is in Phase II clinical trial. This compound (AN-152) consists of doxorubicin attached through a glutaric acid spacer to [D-Lys $\left.{ }^{6}\right]-\mathrm{LH}-\mathrm{RH}[57,58]$. Recent patents claimed LH-RH derivatives including antagonists for the development of conjugates with disorazoles that have cytotoxic effect on human tumor cell lines [59]. However, only the agonist $\left[\mathrm{D}-\mathrm{Lys}^{6}\right]$-LH-RH was mentioned as an example. Targeted tumor therapy based on LH-RH derivatives opens a new way for the efficient and selective treatment of cancer. However, it is still not clear whether LH-RH derivatives with or without endocrine effect would be preferred for targeting anticancer drugs $[45,60]$.

\section{Cetrorelix (CET)}

Cetrorelix, as a third generation LH-RH antagonist, was developed by S. Bajusz in A. V. Schally's laboratory in 1988, when he realized that the presence of D-Arg in position 6 of Ac-D-Nal-D-Cpa-D-Pal-Ser-Tyr-D-Arg-Leu-Arg-ProD-Ala- $\mathrm{NH}_{2}$ antagonistic $\mathrm{LH}-\mathrm{RH}$ analog might be responsible for the oedematogenic effects. The D-isomer of citrulline was incorporated instead of $\mathrm{D}-\mathrm{Arg}^{6}$ into the LH-RH antagonist [15]. This modification resulted in Ac-D-Nal-D-Cpa-DPal-Ser-Tyr-D-Cit-Leu-Arg-Pro-D-Ala- $\mathrm{NH}_{2}$ (SB-75) named cetrorelix, which did not show any oedematous reaction in rats at a dose of $1.5 \mathrm{mg} / \mathrm{kg}$. Furthermore, it was completely free of other toxic effects, such as cyanosis and respiratory depression 
leading to death, that were observed in rats after administration of Ac-D-Nal-D-Cpa-D-Trp-Ser-Tyr-D-Arg-Leu-ArgPro-D-Ala- $\mathrm{NH}_{2}$ and other related antagonists. In preclinical trials, no systemic side effects were found in dogs in both pharmacological and long-term toxicological safety studies [12]. The synthesis and the important pharmacological actions of CET provided a basis for the application of LH-RH antagonists as therapeutic agents [61]. Cetrorelix (Cetrotide ${ }^{\circledR}$; ASTA Medica AG, Frankfurt, Germany) was approved in Europe in 1999 and it was the first LH-RH antagonist to be marketed worldwide. At present, cetrorelix is approved in $>80$ countries including the USA and Japan for the prevention of the premature LH surge in COS. Other indications of CET are sex steroid-dependent benign and malignant conditions, such as uterine leiyomyoma, endometriosis, benign prostatic hyperplasia, prostate and ovarian cancers (in these fields CET still has to be considered as an experimental treatment modality and it should only be used within clinical studies). In all countries except Japan, cetrorelix is marketed by Merck Serono as Cetrotide for use in IVF (in Japan it is marketed by Shionogi and Nippon Kayaku). Æterna Zentaris (Zentaris was established in 2001 as a carve out of ASTA Medica AG and later on it was sold to Æterna Laboratories) receives royalties on these sales and retains rights to develop cetrorelix for other indications.

Cetrorelix was found to be stable in aqueous solutions $(\mathrm{pH}$ 7.0) at RT for a period of 21 days and to be resistant to proteolytic degradation by various enzymes, such as chymotrypsin, pronase and nargase for up to $50 \mathrm{~h}$ at $37^{\circ} \mathrm{C}$ [62]. However, the tendency for aggregation and gel formation, as well as adsorption phenomena in general, had to be reduced. Lyophilization from a properly acidified aqueous solution could prevent these problems. CET could be administered in its acetate form as the physiologically acceptable salt form, as a reconstitute of a lyophilisate [63]. Alternatively, it could be applied as a slightly soluble pamoate microparticle formulation, pamoate salt or pamoate suspension, the latter being the most preferred one [64]. The acidic polyamino acids, polyglutamic acid and polyaspartic acid, were used for complexation with CET resulting in a long acting depot system of the antagonist [65]. It was indicated that a prolonged effect might also require good solubility of the LH-RH antagonists. In a recent patent, a new preparation of an injectable solution of cetrorelix and other antagonists was described [38]. In this mixture, the aggregation of the antagonists was prevented even at high peptide concentrations. The application of organic, physiologically tolerated acids, was preferred for the preparation of such solutions. Gluconic acid in combination with surfactants such as Tween clearly improved the solubility of LH-RH antagonists (e.g., $500 \mathrm{mg}$ CET, 2 g Tween 80, $2.4 \mathrm{~g} \delta$-lactone of gluconic acid and $95 \mathrm{~g}$ of mannitol were mixed with water for injection purposes to form $2 \mathrm{l}$ of a homogeneous solution).

Cetrorelix, which bound to LH-RH membrane receptors on pituitary cells, had a binding affinity $\sim 20$ times higher than the native LH-RH and twice that of the superagonist Buserelin or another investigated antagonist derivative, iturelix. The usefulness of CET in controlled ovarian stimulation for assisted reproductive techniques (COS/ART) was based on the effective suppression of endogenous $\mathrm{LH}$ at a low hormone antagonist concentration, while the suppression of FSH level was not so pronounced [66]. High LH serum concentration might have deleterious effects on the quality of oocytes and reduce pregnancy rates by increasing the progesterone concentration. The minimal effective dose of CET that could prevent premature LH surges and necessary to obtain a good quality of oocytes was $0.25 \mathrm{mg} /$ day using s.c. administration (starting on day 5 or 6 of ovarian stimulation with gonadotropins). In case of a single-dose regimen, $3 \mathrm{mg}$ dose was necessary for efficiency (on day 7) [10,67]. The optimization of the treatment was patented [44]. No significant difference in preventing the premature LH surge was observed using either multiple-dose or single-dose regimens. The single-dose regimen had the advantage of simplicity; however, an estradiol (E2) decrease was detected in some patients.

Cetrorelix has been tested in various diseases of reproductive organs like uterine myoma, benign prostatic hyperplasia, ovarian and prostatic cancers. CET ( $5 \mathrm{mg}$ twice daily for the first 2 days, thereafter $0.8 \mathrm{mg}$ twice daily for 3 months) led to an effective reduction in size and vascularity of the uterus in a shorter treatment period in comparison with LH-RH agonists. The shrinkage of the myoma (uterine volume changed from $395.4 \pm 69.2$ to $230.8 \pm 52.6 \mathrm{ml}$ in an average of 16 patients) without complete suppression of E2 $(>50 \mathrm{pg} / \mathrm{ml})$ was obtained after a 4-week treatment period in a clinical trial using CET depot formulation [68].

To avoid hormone-withdrawal symptoms such as hot flushes and impotence, incomplete testosterone suppression might be sufficient in BPH. The application of CET with a short-term treatment could be effective in this case, as well. In a trial using s.c injections of $1 \mathrm{mg} /$ day CET for 4 weeks, a shrinkage of the prostate and a major improvement of urine flow were observed; nevertheless, the serum concentration of testosterone was lowered only by $\sim 50 \%$ [69]. The improvement of BPH symptoms lasted for several months and it was independent on the prostate size at the study entry. CET is currently undergoing an extensive Phase III clinical trial for the treatment of symptoms associated with $\mathrm{BPH}$.

Cetrorelix, at a dose of $10 \mathrm{mg} /$ day s.c., was shown to be more active on patients with ovarian cancer than an agonistic compound (Phase I/II clinical trial). About half of the patients having progressive disease showed a partial remission or stabilization of their disease [10]. The results were very encouraging and the treatment was further optimized. It was indicated that CET had not only indirect antitumor effect on ovarian cancer cells by suppressing the gonadotropins, but also showed direct antiproliferative activity on them. It was reported that LH-RH receptors were expressed in $\sim 80 \%$ of ovarian cancer cells. Furthermore, experimental data showed that the growth of these receptor positive cells could be inhibited by LH-RH 
analogs. LH-RH antagonists might also act in tumor cells as agonists either through an additional receptor that recognizes LH-RH derivatives or by a different signal transduction pathway induced by type-I LH-RH receptor [54,55]. The results of antiproliferative studies on LH-RH-IR knockout cells suggested that the antiproliferative effects of CET were not or not only mediated through the LH-RH-IR. However, the elucidation of the mechanism of action requires further investigations.

In the case of patients with biopsy-proven prostatic cancer, a dose of $0.5 \mathrm{mg}$ CET s.c. twice daily for 6 weeks was administered. The testosterone level decreased immediately to subnormal concentrations, reaching a nadir after $6-12 \mathrm{~h}$ and after 6 weeks of therapy the total serum testosterone level was below the castration concentration $(2 \mathrm{nM})$. Better results and faster achievement of the castration concentration was obtained using a dose of $10 \mathrm{mg}$ daily for $2-5$ days followed by a daily dose of $1-2 \mathrm{mg}$ to maintain the castration concentration of testosterone. During the treatment, fast improvement (in about 1 week) of disease-related symptoms (bone pain, paraeshesia and paraplegia relief of urinary flow obstruction) was observed. A progressive decrease in the prostate volume was obtained after the second week of treatment [12]. Other treatment protocols have been developed and patented. For example, a treatment scheme comprised the following steps: i) the administration of an initial dose of LH-RH analogs over a first period, this dose being sufficient to achieve hormonal castration; ii) the administration of a maintenance dose of an LH-RH antagonist over a second period; and iii) optionally, the repetition of steps i) and ii) [36].

The advantage of CET in comparison with LH-RH agonists is that no co-medication with anti-androgens is required. Consequently, the cost difference between the treatments with the more expensive CET and LH-RH agonists decreases.

Recently, it has been demonstrated that cetrorelix affected brain function and it was able to correct the impairment of the memory consolidation caused by the $\beta$-amyloid $25-35$ [70]. CET also elicited anxiolytic and antidepressive action, but it did not influence the open-field activity. Further experimental work with cetrorelix is necessary; however, these patented results suggest that the inhibition of gonadotropins could represent a new target for the therapeutic intervention in anxiety, depression and Alzheimer's disease [71].

\section{Abarelix}

Abarelix (Ac-D-Nal-D-Cpa-D-Pal-Ser-N-MeTyr-D-AsnLeu-Lys(iPr)-Pro-D-Ala- $\mathrm{NH}_{2}$ ) differs from cetrorelix in positions 5, 6 and 8, where $\mathrm{Tyr}^{5}$ is replaced by N-MeTyr, D-Cit ${ }^{6}$ by $\mathrm{D}$-Asn and $\mathrm{Arg}^{8}$ by Lys(iPr) [16]. Abarelix efficiently decreases not only the LH but also the FSH secretion, effect which is significantly higher than that caused by cetrorelix. This effect prevents the application of abarelix in COS/ART procedure in which the decrease of FSH is not preferred.

It was shown that FSH could stimulate the proliferation of human androgen-resistant prostate cancer in vitro [72]. This observation suggested that LH-RH antagonists having not only LH but also significant FSH suppression effect might have clinical implications in cancer therapy [26,29]. Methods for treating FSH-related conditions (e.g., prostatic intraepithelial neoplasia, prostate-, testicular-, ovarian-, and breast cancers, benign prostatic hypertrophy, endometriosis, uterine fibroids, premenstrual syndrome, polycystic ovary syndrome, pituitary gonadotropin tumors) by LH-RH antagonists suitable for in vivo use have been recently patented [73]. Abarelix was very efficient for the treatment of prostate cancer and it was the only LH-RH antagonist introduced into the market as an antineoplastic agent.

In comparison with the LH-RH agonists (e.g., leuprolide), the administration of abarelix resulted in an immediate decrease of LH, testosterone (T), dihydrotestosterone (DHT) and prostate-specific antigens (PSA) levels. By day 8 after abarelix administration, $\sim 75 \%$ of the patients reached the castrate levels of testosterone $(<5 \mathrm{ng} / \mathrm{ml})$ without testosterone surge compared with $0 \%$ of LH-RH agonist-treated patients [74]. Abarelix given as a $50 \mu \mathrm{g} / \mathrm{kg} /$ day s.c. infusion over 3 months was sufficient to produce clinically significant effects [75]. Furthermore, the depot formulation of abarelix led to the elevation of its bioavability. The comparison between a single dose of $15 \mathrm{mg} / \mathrm{kg}$ abarelix injectable solution and $100 \mathrm{mg}$ abarelix depot showed the advantages of the depot formulation [76]. The half life of abarelix was $5.3 \mathrm{~h}$ at the single injection and 13.2 days at abarelix depot administration. In the first case, the mean inhibition of T, DHT, LH and FSH was 76.5, 65.2, 76.5 and $33.6 \%$, respectively. Significantly higher inhibition of these biomarkers (especially FSH) was detected using the depot form of abarelix (93.6, 88.5, 94.6 and 71.2\%, respectively) [77].

Compared to LH-RH agonists, abarelix showed clear benefits such as the absence of flare, rapid downregulation, the avoidance of combination therapy with anti-androgens (e.g., flutamide, bicalutamide), that improved compliance, decreased side effects and lowered the costs. Abarelix was well tolerated in both injectable solution and depot form; no antibody production was detected and no significant histamine release was observed during the treatments. However, some disadvantages limited its clinical use. The most frequently reported adverse events were decreased libido or symptoms of upper respiratory tract disorders (bronchitis), fever, headaches and hot flushes. Due to these side effects, in 2003 FDA approved the application of abarelix $\left(\right.$ Plenaxix $^{\circledR}$ ) only for patients with advanced, symptomatic prostate cancer who could not have or who refused other treatments. The administration of abarelix could also be associated with an acute systemic allergic reaction ( $1.1 \%$ of the treated patients) occurring within $8 \mathrm{~min}$ after injection [26,78]. Therefore, in 2005 Praecis Pharmaceuticals voluntarily discontinued the use of abarelix in the US and abarelix was not applied for cancer therapy any longer. In the same year, abarelix was approved in Germany under the license of Speciality European Pharma.

Some of the side effects derived from the androgen decline, suppression or abrogation might be reduced by applying a 
composition consisting of a selective androgen receptor modulator (SARM) and an LH-RH antagonist [79].

\section{Ganirelix}

In the early 1990s, J. Nestor and his colleagues prepared various LH-RH antagonists with the aim of generating compounds that had not only decreased mast cell degranulation potency resulting in lower histamine release and allergic side effects, but also increased antiovulatory potency [17]. This dual activity was needed because of the fact that previous LH-RH antagonists required substantially higher doses $(5-20 \mathrm{mg} /$ day) than those of agonists ( $\leq 1 \mathrm{mg} /$ day) in their paradoxical, antifertility applications. The work of Nestor et al. led to the identification of ganirelix (Ac-D-Nal-D-Cpa-D-Pal-Ser-Tyr$\mathrm{D}-\mathrm{h} \operatorname{Arg}(\mathrm{Et})_{2}$-Leu-hArg(Et ${ }_{2}$-Pro-D-Ala- $\left.\mathrm{NH}_{2}\right)$, compound which had the above-mentioned properties and underwent advanced pharmacological studies.

Ganirelix acetate acted by competitively blocking the LHRH-Rs on the pituitary gonadotroph and subsequent transduction pathway. It induced a rapid, reversible suppression of gonadotropin secretion ( $\mathrm{LH}$ was more pronounced than FSH). The administration of ganirelix acetate did not result in an initial release of endogenous gonadotropins, indicating an antagonistic effect. Upon discontinuation of ganirelix acetate, pituitary $\mathrm{LH}$ and FSH levels were fully recovered within $48 \mathrm{~h}$. The effective dose of ganirelix acetate was $250 \mathrm{\mu g} /$ day using s.c. injection [65].

The elimination half-life of ganirelix after single dose administration was about $13 \mathrm{~h}$, which was longer than that of cetrorelix (between 5 and $10 \mathrm{~h}$ ). However, both compounds seemed to be equipotent regarding gonadotropin suppression, being fully effective within $4-8 \mathrm{~h}$ after administration [80]. Ganirelix is marketed by Organon International as Antagon ${ }^{\circledR}$ and primarily used in assisted reproduction to control ovulation.

During the last years, the main research direction with ganirelix was to optimize its use in clinical treatments. Recently, it has been indicated that without some cycle programming methods such as oral contraceptive (OC) pretreatment, the timing of oocyte retrieval or intrauterine insemination (IUI) was dependent on the onset of the menstrual cycle, making antagonist regimens less attractive for programs and patients who needed the flexibility of scheduling of these procedures. Unfortunately, OC pretreatment combined with a full dose of antagonist $(250 \mu \mathrm{g} /$ day $)$ caused a marked suppression of LH levels, and in some women increased early pregnancy loss [81]. Although supplementing LH might apparently counteract these adverse effects [82], the addition of another medication would complicate the controlled ovarian hyperstimulation procedure. Meldrum et al. suggested that OC pretreatment with half of the usual dose of ganirelix $(125 \mu \mathrm{g} /$ day $)$ could be an excellent choice for patientfriendly reduced stimulation IVF or for IUI cycles where flexibility was required for scheduling [83].
In order to be suitable for IUI, further studies of the optimal starting dose of FSH and/or a later onset of stimulation following cessation of OC are necessary.

\section{LH-RH antagonists: new candidates for clinical applications}

The development of new LH-RH antagonists is mainly focused on the improvement of the duration of action. Azaline B and acyline that differ from abarelix in positions 5 and 6 (Table 1) are among the most potent long-acting derivatives; however, their relatively low solubility prevents the effective use in clinically acceptable volumes (s.c. administration) in order to achieve the inhibition of gonadotropins for 4 weeks. There is an inverse relationship between the concentration and the bioavailability in the case of these compounds [84]. Further improvement of LH-RH antagonists has to be focused on the increase of the solubility of the long-acting compounds.

One of the most potent $\mathrm{LH}-\mathrm{RH}$ antagonists as a candidate for future clinical use is degarelix developed by Jiang et al. [18]. They introduced urea and carbamoyl functionalities in positions 5 and $6(\sim 40$ new derivatives were prepared), which prevented the formation of $\beta$-structures that were shown to be responsible for gel formation [85]. Some of these compounds had solubilities as high as $50 \mathrm{mg} / \mathrm{ml}$, and they commonly might be used as $5-10 \mathrm{mg} / \mathrm{ml}$ solutions at $\mathrm{pH} 5.4$. Studies of administrations suggested that $2.5 \mathrm{mg} / \mathrm{ml}$ parenterally and $1 \mathrm{mg} / \mathrm{ml}$ s.c. administration in appropriate solutions could be used without the danger of gelling at the point of injection [86]. It was found that degarelix was not only more soluble than the above-mentioned antagonists but also its activity lasted much longer. It was also hypothesized that the ability of the new compounds to form hydrogen bonds increased both their solubility and the intermolecular structure stabilization between the peptide and its receptor. Nevertheless, the affinity of degarelix for the LH-RH-R was not significantly different from that of ganirelix, abarelix, cetrorelix, etc., meaning that the receptor affinity was not responsible for the increase in the duration of action [18,30]. Using a dose of $2 \mathrm{mg}$ degarelix $/ \mathrm{kg}$ body weight s.c. abolished the plasma testosterone level (below the castration level) till the day 50. Furthermore, in contrast to cetrorelix and similarly to abarelix, degarelix had only weak histamine-releasing properties in vitro $\left(\mathrm{EC}_{50}\right.$ values for cetrorelix, ganirelix, azaline B, abarelix, degarelix was $1.3,11,19$, $100,170 \mu \mathrm{g} / \mathrm{ml}$, respectively).

In the last years, the dose of degarelix was optimized in various clinical trials for prostate cancer [87]. Evidence accumulated to date indicated that an initial dose of $240 \mathrm{mg}$ with a maintenance dose of 80 and $160 \mathrm{mg}$ degarelix every 4 weeks was the optimal dose to achieve clinically relevant testosterone suppression. The recent large, randomized Phase III study in patients with prostate cancer provided preliminary evidence for the potential advantages of degarelix over LH-RH agonists $[88,89]$. Despite the disadvantage that degarelix is 


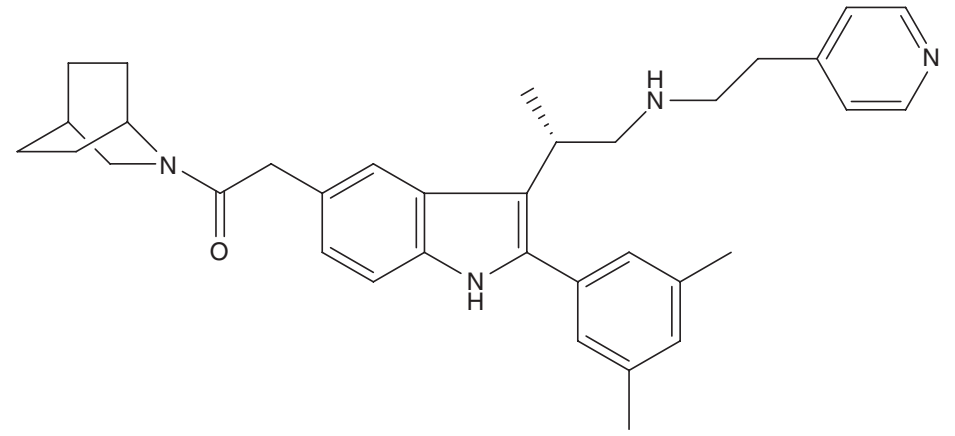

Indol type (Merck)

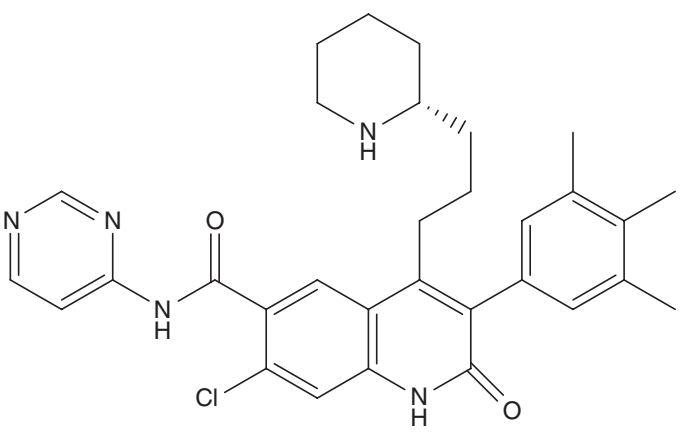

Quinolinone type (Merck)

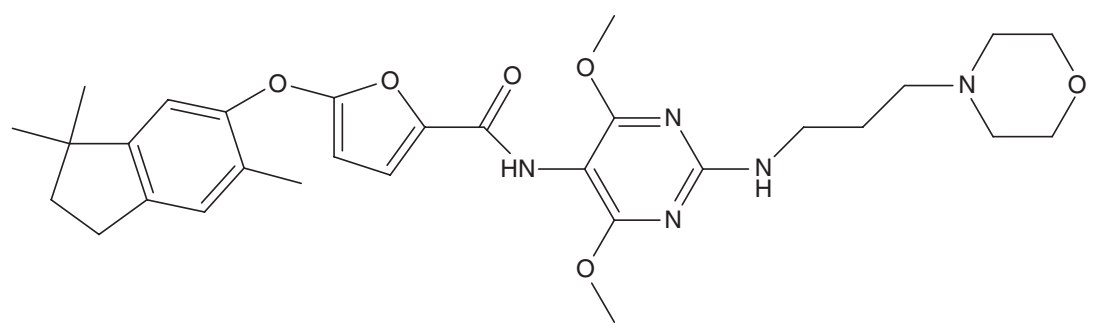

Furamide type (Pfizer)

Figure 3. Chemical structures of various classes of non-peptidic luteinizing hormone-releasing hormone antagonists.

currently available only as an 1-month formulation, it has been approved by the FDA for the treatment of advanced prostate cancer in December 2008 and its approval by the European Medicines Agency has been recommended [90].

A lot of effort was undertaken to increase the efficacy, solubility and enzymatic stability of degarelix. In a recent study, 31 degarelix analogs were prepared; however, none of them was better than degarelix itself [91]. Nine new azaline B analogs (azaline B differs from degarelix in the substitution of Aph derivatives in positions 5 and 6) were also synthesized; however, they did not provide better results either [92].

Based on the study of the structure-activity relationship of cetrorelix analogs (linear, branched and cyclic peptides), ozarelix as a highly water soluble LH-RH antagonist was also prepared [20]. Ozarelix had similar binding affinity and antagonistic potency to LH-RH-R as cetrorelix. However, high binding affinity and antagonistic potency in vitro were no guarantee for long duration of testosterone suppression in vivo. The serum testosterone concentration increased from the castration level up to the normal level in 4 days in the case of ozarelix and in 15 days in the case of cetrorelix. This difference could be explained by the pharmacokinetics of the compounds. Peptides like cetrorelix injected subcutaneously formed a local depot and small amounts of antagonist were continuously released. In contrast to cetrorelix, ozarelix was not detected in rat serum after $24 \mathrm{~h}$ using $0.4 \mathrm{mg} / \mathrm{kg}$ s.c. Thus, solubility in aqueous buffers is one important factor for peptide bioavailability (the solubility of these peptides in aqueous buffers was quite different: $0.002 \mathrm{mg} / \mathrm{ml}$ for cetrorelix and $0.75 \mathrm{mg} / \mathrm{ml}$ for ozarelix). In a patent on the preparation of injectable solutions it was mentioned that $50 \mathrm{ml}$ clear solution could be prepared from $500 \mathrm{mg}$ ozarelix [39].

Ozarelix might be very effective for the treatment of $\mathrm{BPH}$ and it is in Phase II clinical trial as lead compound of Æterna Zentaris [93]. Patented results indicated that ozarelix was well tolerated and had statistically significant as well as clinically meaningful efficacy in the treatment of lower urinary tract symptoms secondary to BPH [94].

\section{Orally active non-peptidic antagonists of LH-RH receptors}

Peptidic LH-RH antagonists are usually administered by s.c. or i.m. injection or by a sustained delivery system. However, in the last years intensive research were undertaken to develop small organic molecules that could antagonize the LH-RH receptors and had the potential to be orally bioavailable.

The oral route of administration represents the easiest way of treatment and the most convenient one for the patients. Furthermore, the oral administration provides a level of control over the degree of pituitary suppression that is simply not available with the down-regulating agonists or one-size-fits-all antagonist depot. The major reason for the development of non-peptidic LH-RH antagonists is that both peptidic 


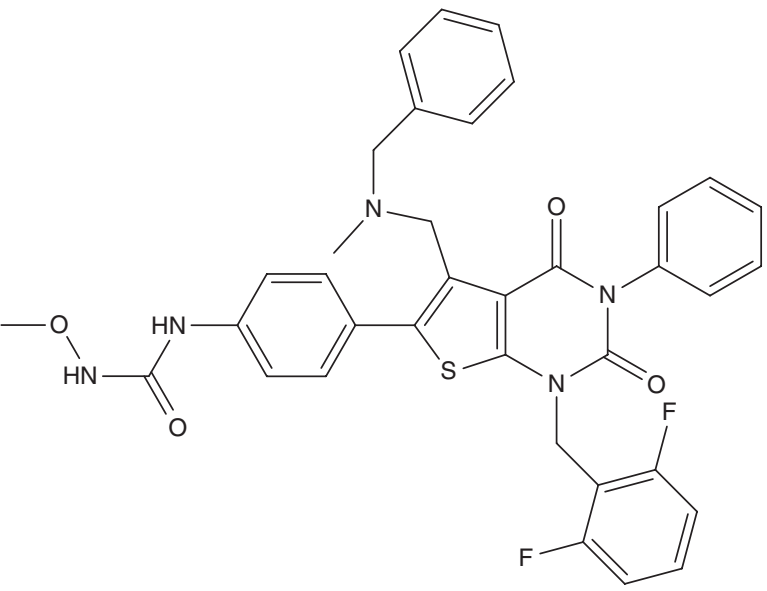

Thienopyrimidinedione type (Takeda)

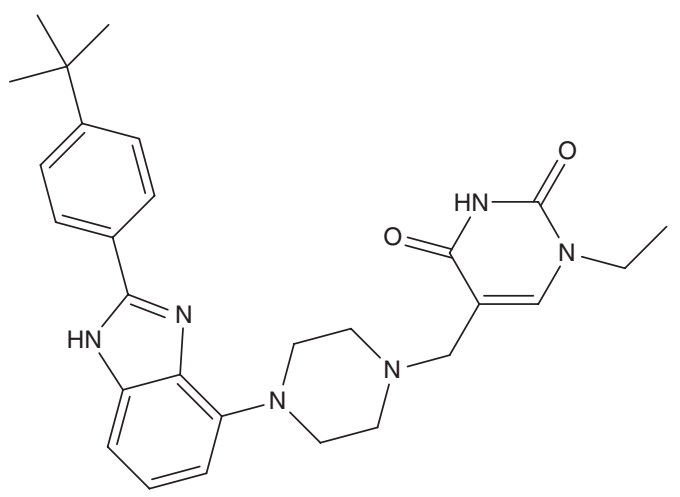

Piperazinylbenzimidazole type [92]

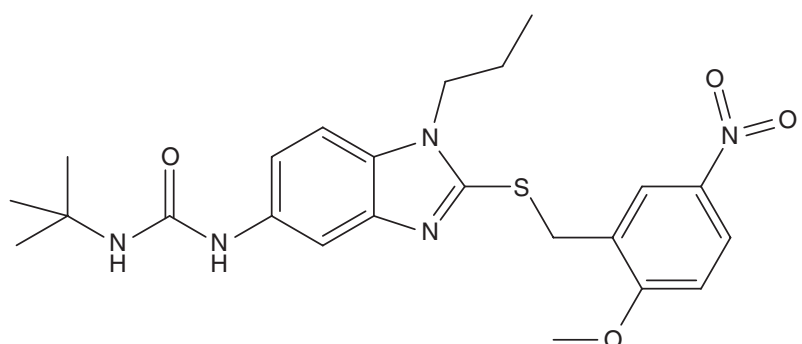

Benzimidazole type (Bayer)

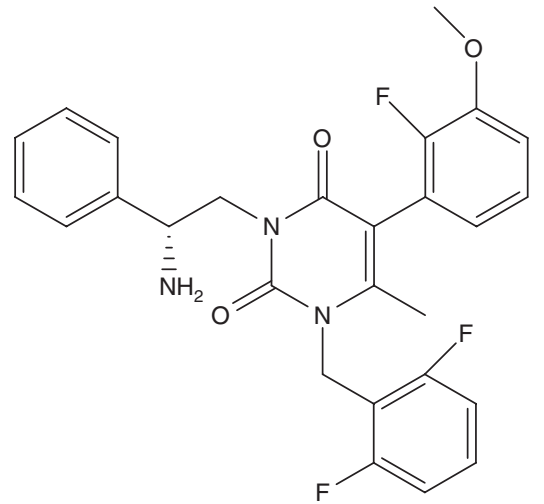

Uracil type (Neurocrine)

Figure 3. Chemical structures of various classes of non-ptidic luteinizing hormone-eleasing hormone antagonists. (continued)

superagonists and antagonists of LH-RH have poor pharmacokinetic and bioavailability properties when taken orally [95].

Recently, different chemical classes of non-peptidic LH$\mathrm{RH}$ antagonists have been described. A detailed list of the compounds as well as the corresponding references and 31 patents have been presented in a recent publication [96]. Thienopyrimidinediones, thienopyridinones, quinolinones, indoles, furamides, uracils, benzimidazoles, piperazinylbenzimidazoles, etc. were found as effective LH-RH receptor blockers in $\mathrm{nM}$ and $\mu \mathrm{M}$ range [95-97]. The activity of these structurally diverse compounds (Figure 3 ) on a single receptor might be explained by their binding to different subregions of the receptor active site. Due to the structural diversity of these compounds, their selectivity that might be much lower than in the case of peptides should be carefully studied. Despite the broad chemical diversity of high affinity ligands to human LH-RH-R, very few have led to drug candidates and entered clinical trials so far. One reason might be that small molecule association with LH-RH-R can be species selective. Therefore, many compounds may require preclinical studies in expensive monkey models.

Neurocrine Biosciences, Inc., reported on elagolix (Sodium R-(+)-4-\{2-[5-(2-Fluoro-3-methoxyphenyl)-3-(2-fluoro6-[trifluoromethyl]-benzyl)-4-methyl-2,6-dioxo-3,6-dihydro2H-pyrimidin-1-yl]-1-phenylethylamino\}butyrate) (Figure 4) which is currently in Phase II clinical trial in women with endometriosis [98,99]. The first reported results showed that elagolix was well tolerated and bioavailable after oral administration. Serum gonadotropins declined rapidly without any flare. Daily (50 - $200 \mathrm{mg})$ or twice-daily (100 mg) administration for 7 days maintained low estradiol levels $(17 \pm 3$ to $68 \pm 46 \mathrm{pg} / \mathrm{ml}$ ) in most subjects during late follicular phase. Furthermore, the effects of the compound were rapidly reversed after discontinuation [100].

Preclinical and clinical studies that are in progress will reveal in the future whether the non-peptidic LH-RH antagonists are 


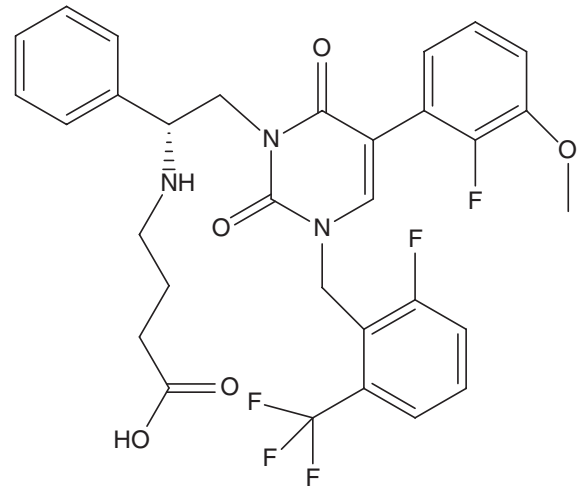

Figure 4. Chemical structure of the non-peptidic luteinizing hormone-releasing hormone antagonist elagolix.

more advantageous than the peptide based therapy of IVF, $\mathrm{BPH}$, and cancer.

\section{Expert opinion}

The hormone-dependent tumors such as breast, prostate and endometrial cancers are widespread especially in developed countries and are a major cause of mortality in many cases. The hormone therapy alone or in combination with surgery, irradiation or chemotherapy represents a main treatment modality. Hormone therapy is also beneficial in treating benign prostatic hyperplasia and endometriosis, as well as in in vitro fertilization, events that depend either directly on the gonadotropin hormones or on their influence on the sex-steroid hormones. Therefore, the treatments are based on the reduction of the gonadotropin level in the blood. The evidence that LH-RH agonists and antagonists influence the gonadotropin secretion makes these compounds lead structures for the development of therapeutic agents. The advantages of antagonists over agonists are clearly due to the avoidance of the 'flare-up effect' caused by the agonists. However, some drawbacks of the antagonists such as allergic side reactions, low solubility and unclear treatment schedules make the agonists still more attractive for various clinical applications. The development of effective LH-RH antagonists and consequently the patent claims in this area are focused on minimizing the histamine release and allergic side reactions as well as on increasing their solubility. Furthermore, the optimization of the treatment schedules is an important issue.
Up to now, $10-15$ third and fourth generation LH-RH antagonists selected from hundreds of compounds are on the market (cetrorelix, ganirelix and abarelix) or in clinical trials. These compounds differ mainly in the amino acid derivatives in positions $5-8$. It seems that it is more and more difficult to design better compounds than the ones currently in clinical use, without modifying the essential parts (sequences $1-4$ and $9-10)$ of the antagonists. Cetrorelix and ganirelix are very efficient in IVF. However, in tumor therapy in which high doses should be applied, the insolubility of the compounds as well as the increased histamine release might limit their efficacy without finding a good formulation for 'patient friendly' treatment. The example of abarelix which was withdrawn in the USA because of allergic side reactions warn us that only compounds without significant side effects might be good drug candidates. Degarelix and ozarelix have increased solubility and have less effect on histamine release; thus, these two compounds might be the most potent analogs in the future.

The fact that LH-RH analogs have direct antiproliferative effect on cancer cells, which is mediated through the LH-RHRs, has open a new direction in the therapeutic applications of LH-RH derivatives. The synergism of indirect and direct antitumor activity of LH-RH derivatives, as well as the combination of compounds that have indirect and direct effect on tumor cells, should be studied in detail in order to increase their efficacy.

Recently, numerous non-peptidic LH-RH antagonists have been developed, but only a few of them are currently in clinical trials. The results of these studies will show whether they are suitable for the treatment of reproductive disorders. However, it is evident that peptides are usually more selective than the small organic compounds. Nevertheless, the attractive choice of oral administration suggests the merit of further development of orally active non-peptidic LH-RH-R blockers.

\section{Acknowledgements}

The authors thank S Bajusz and M Kovács for critically reading the manuscript and for their advice.

\section{Declaration of interest}

The authors state no conflict of interest and have received no payment in preparation of this manuscript. 


\section{Bibliography}

Papers of special note have been highlighted as either of interest $(\bullet)$ or of considerable interest $(\bullet \bullet)$ to readers.

1. Matsuo H, Baba Y, Nair RM, et al. Structure of the porcine LH- and FSH-releasing hormone. I. The proposed amino acid sequence. Biochem Biophys Res Commun 1971;43:1334-9

2. Kastin AJ, Coy DH, Schally AV, Zadina JE. Dissociation of effects of LH-RH analogs on pituitary regulation and reproductive behavior. Pharmacol Biochem Behav 1980;13:913-4

3. Carmel PW, Araki S, Ferin M. Pituitary stalk portal blood collection in rhesus monkeys: evidence for pulsatile release of gonadotropin-releasing hormone $(\mathrm{GnRH})$. Endocrinology 1976;99:243-8

4. Redding TW, Kastin AJ, Gonzales-Barcena D, et al. The half-life, metabolism and excretion of tritiated luteinizing hormone-releasing hormone (LH-RH) in man. J Clin Endocrinol Metab 1973;37:626-31

5. Belchetz PE, Plant TM, Nakai Y, et al. Hypophysial responses to continuous and intermittent delivery of hypopthalamic gonadotropin-releasing hormone. Science 1978;202:631-3

6. Schultze-Mosgau A, Griesinger G, Altgassen C, et al. New developments in the use of peptide gonadotropin-releasing hormone antagonists versus agonists. Expert Opin Investig Drugs 2005;14:1085-97

7. Millar RP. GnRHs and GnRH receptors. Anim Reprod Sci 2005;88:5-28

8. Schally AV, Nagy A. New approaches to treatment of various cancers based on cytotoxic analogs of LHRH, somatostatin and bombesin. Life Sci 2003;72:2305-20

9. Padula AM. GnRH analogues - agonists and antagonists. Anim Reprod Sci 2005;88:115-26

10. Coccia ME, Comparetto C, Bracco GL, Scarselli G. GnRH antagonists. Eur J Obstet Gynecol Reprod Biol 2004;115S:44-56

11. Huirne JA, Homburg R, Lambalk CB. Are GnRH antagonists comparable to agonists for use in IVF? Hum Reprod 2007;22:2805-13

12. Reissmann T, Schally AV, Bouchard P, et al. The LHRH antagonist cetrorelix: a review. Hum Reprod Update 2000;6:322-31

13. Trachtenberg J. Emerging pharmacologic therapies for prostate cancer. Rev Urol 2001;3:S23-8

14. Schmidt F, Sundaram K, Thau RB, Bardin CW. [Ac-D-NAL(2)1,4FD-Phe2, D-Trp3,D-Arg6]-LHRH, a potent antagonist of LHRH, produces transient edema and behavioral changes in rats. Contraception 1984;29:283-9

15. Bajusz S, Csernus VJ, Janáky T, et al. New antagonists of LHRH. II. Inhibition and potentiation of LHRH by closely related analogues. Int J Pept Protein Res 1988;32:425-35

16. Cook T, Sheridan WF. Development of $\mathrm{GnRH}$ antagonists for prostate cancer: new approaches to treatment. Oncologist 2000;5:162-8

17. Nestor JJ Jr, Tahilramani R, Ho TL, et al. Potent gonadotropin releasing hormone antagonists with low histamine-releasing activity. J Med Chem 1992;35:3942-8

18. Jiang G, Stalewski J, Galyean R, et al. GnRH antagonists: a new generation of long acting analogues incorporating p-ureido-phenylalanines at positions 5 and 6. J Med Chem 2001;44:453-67

19. Deghenghi R, Boutignon F, Wüthrich P, Lenaerts V. Antarelix (EP 24332) a novel water soluble LHRH antagonist. Biomed Pharmacother 1993;47:107-10

20. Beckers T, Bernd M, Kutscher B, et al. Structure-function studies of linear and cyclized peptide antagonists of the $\mathrm{GnRH}$ receptor. Biochem Biophys Res Commun 2001;289:653-63

21. Janecka A, Janecki T, Shan S, et al. Novel, potent luteinizing hormone-releasing hormone antagonists withis in water. J Med Chem 1994;37:2238-41

22. Phillips A, Hahn DW, McGuire JL, et al. Evaluation of the anaphylactoid activity of a new LHRH antagonist. Life Sci 1988;43:883-8

23. Rivier JE, Jiang G, Porter J, et al. Gonadotropin-releasing hormone antagonists: novel members of the azaline B family. J Med Chem 1995;38:2649-62

24. Rivier J, Porter J, Hoeger C, et al Gonadotropin-releasing hormone antagonists with $\mathrm{N}$ omega-triazolylornithine, -lysine, or -p-aminophenylalanine residues at positions 5 and 6. J Med Chem 1992;35:4270-8

25. Herbst KL. Gonadotropin-releasing hormone antagonists.

Curr Opin Pharmacol 2003;3:660-6

26. Huhtainemi I, White R, McArdle CA, Persson B-E. Will GnRH antagonists improve prostate cancer treatment? Trends Endocrinol Metabol 2008;20:43-50

27. Debruyne F, Gres AA, Arustamov DL. Placebo-controlled dose-ranging phase 2 study of subcutaneously administered LHRH antagonist cetrorelix in patients with symptomatic benign prostatic hyperplasia. Eur Urol 2008;54:170-7

28. Kovács M, Szepesházi K, Schally AV. Endocrine and antineoplastic effects of antagonistic and cytotoxic analogs of luteinising hormone-releasing hormone. In: Kovács M, Merchenhalter I, editors, Neuropeptides and peptide analogs. Research Signpost, Kerela, India; 2009. p. 33-57

29. Weckermann D, Harzman R. Hormone therapy in prostate cancer: $\mathrm{LHRH}$ antagonists versus LHRH analogues. Eur Urol 2004;46:279-84

30. Broqua P, Riviere PJ, Conn PM, et al. Pharmacological profile of a new, potent, and long-acting gonadotropin-releasing hormone antagonist: degarelix. J Pharmacol Exp Ther 2002;301:95-102

31. Ferring BV. GnRH antagonists. US5925730; 1999

32. Bernd M, Kutscher B, Gunther E, et al. Methods of treatment using novel LHRH antagonists having improved solubility properties. US20060281685; 2006

33. Kissei Pharmaceutical Co., Ltd. Fused heterocyclic derivative, medicinal composition containing the same, and medicinal use thereof. EP1939204; 2008, WO2007046392; 2007

- Important patent describing non-peptidic LH-RH antagonists.

34. Ardana Bioscience Ltd. Sustained release of microcrystalline peptide suspension. US20060229238; 2006

35. Praecis Pharmaceutical, Inc. Pharmaceutical formulations for sustained drug delivery. WO2007022254; 2007

- Important patent description for sustained delivery formulation of 
water-insoluble complex of peptidic compounds such as LH-RH antagonists.

36. AEterna Zentaris GmbH. Application of initial doses LHRH analogues and maintenance doses of LHRH antagonists for the treatment of hormone-dependent cancers and corresponding pharmaceutical kits. WO2008017664; 2008, US20080032935; 2008, EP1891964; 2008

-• Important patent describing efficient dosage of LH-RH antagonist in cancer therapy.

37. Balance Pharmaceutical, Inc. Nasal-spray formulation and method. US6958142; 2005

38. AEterna Zentaris GmbH. Injectable solution of an LHRH antagonist. US7214662; 2007

- Important patent description of solution ingredients for preparation of injectable solutions of LH-RH antagonists (e.g., cetrorelix and ozarelix).

39. Edwards RG, Lobo R, Bouchard P. Time to revolutionize ovarian stimulation. Hum Reprod 1996;11:917-9

40. Janssens RM, Lamback CB, Vermeiden JP, et al. Dose-finding study of triptorelin acetate for prevention of premature LH surge in IVF: a prospective, randomized, double-blind, placebo-controlled study. Hum Reprod 2000;15:2333-40

41. Tarlatzis BC, Fauser BC, Kolibianakis EM, et al. GnRH antagonists in ovarian stimulation for IVF. Hum Reprod Update 2006; 12:333-40

42. Fauser BC, Devroey P, Macklon NS. Multiple birth resulting from ovarian stimulation for subfertility treatment. Lancet 2005;365:1807-16

43. Verberg MF, Macklon NS, Nargund G, et al. Mild ovarian stimulation for IVF. Hum Reprod Update 2009;15:13-29

44. AEterna Zentaris GmbH. LHRH-antagonists in the treatment of fertility disorders. US7393834; 2008

- Important patent describing efficient treatment circumstances for fertility disorders.

45. Mező G, Manea M, Szabó I, et al. New derivatives of $\mathrm{GnRH}$ as potential anticancer therapeutic agents. Curr Med Chem 2008;15:2366-79

46. Brawer MK. The evolution of hormonal therapy for prostatic carcinoma. Rev Urol 2001;3S:1-9
47. Emons G, Gründker C, Günthert AR, et al. $\mathrm{GnRH}$ antagonists in the treatment of gynecological and breast cancers. Endocr Relat Cancer 2003;10:291-9

48. Keller G, Schally AV, Gaiser T, et al. Receptors for luteinizing hormone releasing hormone (LHRH) expressed in human non-Hodgkin's lymphomas can be targeted for therapy with cytotoxic LHRH analogue AN-207. Eur J Cancer 2005;41:2196-202

49. Gründker C, Günthert AR, Westphalen S, Emons G. Biology of the gonadotropin-releasing hormone system in gynecological cancers. Eur J Endocrinol 2002;146:1-14

50. Leung PC, Choi JH. Endocrine signaling in ovarian surface epithelium and cancer. Hum Reprod Update 2007;13:143-62

51. Conn PM, Crowley WF Jr. Gonadotropin-releasing hormone and its analogs. Annu Rev Med 1994;45:391-405

52. Sealfon SC, Weinstein H, Millar RP. Molecular mechanisms of ligand interaction with the gonadotropin-releasing hormone receptor. Endocr Rev 1997;18:180-205

53. Gründker C, Völker P, Günthert AR, Emons G. Antiproliferative signaling of LHRH in human endometrial and ovarian cancer cells through G-protein $\alpha \mathrm{i}$-mediated activation of phosphotyrosine phosphatase. Endocrinology 2001;142:2369-80

54. Maudsley S, Davidson L, Pawson AJ, et al. Gonadotropin-releasing hormone $(\mathrm{GnRH})$ antagonists promote proapoptotic signaling in peripheral reproductive tumor cells by activating a Galphai-coupling state of the type I GnRH receptor. Cancer Res 2004;64:7533-44

55. Gründker C, Schlotawa L, Viereck V, et al. Antiproliferative effects of the $\mathrm{GnRH}$ antagonist cetrorelix and of GnRH-II on human endometrial and ovarian cancer cells are not mediated through the $\mathrm{GnRH}$ type I receptor. Eur J Endocrinol 2004;151:141-9

56. Fister S, Günthert AR, Emons G, Gründker C. Gonadotropin-releasing hormone type II antagonists induce apoptotic death in human endometrial and ovarian cancer cells in vitro and in vivo. Cancer Res 2007;67:1750-6

57. Nagy A, Schally AV, Armatis P, et al. Cytotoxic analogs of luteinizing hormone-releasing hormone containing doxorubicin or 2-pyrrolinodoxorubicin, a derivative 500-1000 times more potent. Proc Natl Acad Sci USA 1996;93:7269-73

58. Tulane Educational Fund. Targeted cytotoxic anthracycline analogs. US6184374; 2001

- Important patent describing the first cytotoxic LH-RH derivative that reached the Phase II clinical trial.

59. AEterna Zentaris GmbH. Conjugates of disorazoles and their derivatives with cell-binding molecules, novel disorazole derivatives, processes of manufacturing and uses thereof. US20080090758; 2008

- Important patent describing dimeric forms of LH-RH derivatives for targeted tumor therapy.

60. Szabó I, Manea M, Orbán E, et al. Development of an oxime bond containing daunorubicin-gonadotropin-releasing hormone-III conjugate as a potential anticancer drug. Bioconjug Chem 2009;20:656-65

61. Tulane Educational Fund. LHRH antagonists. US5198533; 1993

62. Reissmann T, Engel J, Kutscher B, et al. The LHRH antagonist Cetrorelix. Drugs Future 1994;19:228-37

63. AEterna Zentaris GmbH. Preparation and use of oligopeptide lyophilisate for gonad protection. US6867191; 2005

64. AEterna Zentaris GmbH. Method for producing steril suspensions or lyophilisates of poorly soluble basic peptide complexes, pharmaceutical formulations containing the same, and use thereof as medicaments. WO2006069641; 2006

65. Asta Medica Aktiengesellschaft. Immobilized and activity-stabilized complexes of LHRH antagonists and processes for their preparation. US6022860; 1998

66. Matikainen T, Ding YQ, Vergara M, et al Differing responses of plasma bioactive and immunoreactive follicle-stimulating hormone and luteinizing hormone to gonadotropin-releasing hormone antagonist and agonist treatments in postmenopausal women. J Clin Endocrinol 1992;7:820-5

67. Olivennes F, Cuncha-Filho JS, Fanchin R, et al. The use of GnRH antagonists in ovarian stimulation. Hum Reprod Update 2002;8:279-90

68. Gonzalez-Barcena D, Alvarez RB, Ochoa EP, et al. Treatment of uterine 
leiomyomas with luteinizing hormone-releasing hormone antagonist Cetrorelix. Hum Reprod 1997;12:2028-35

69. Comaru-Schally AM, Brannan W, Schally AV, et al. Efficacy and safety of luteinizing hormone-releasing hormone antagonist cetrorelix in the treatment of symptomatic benign prostatic hyperplasia. J Clin Endocrinol Metab 1998;83:3826-31

70. Telegdy G, Tanaka M, Schally AV. Effects of the LHRH antagonist Cetrorelix on the brain function in mice. Neuropeptides 2009;43:229-34

71. AEterna Zentaris GmbH. Treatment of dementia and neurodegenerative diseases with intermediate doses of LHRH antagonists. US7288517; 2007

- Important patent describing the treatment of dementia and neurodegenerative diseases like Alzheimer's disease with cetrorelix.

72. Ben-Josef E, Yang SY, Ji TH, et al. Hormone-refractory prostate cancer cells expresses functional follicle-stimulating hormone receptor (FSHR). J Urol 1999;161:970-6

73. Praecis Pharmaceuticals, Inc. Methods for treating FSH related conditions with GnRH antagonists. US7109171; 2007

-• Important patent describing the application of LH-RH antagonists for FSH-related diseases.

74. Tomera K, Gleason D, Gittelman M, et al. The gonadotropin-releasing hormon antagonist abarelix depot versus luteinizing hormone releasing hormone agonists leuprolide or goserelin: initial results of endocrinological and biochemical efficacies in patients with prostate cancer. J Urol 2001;165:1585-9

75. Wong SL, Lau DT-W, Baughman SA, et al. Pharmacokinetics and pharmacodynamics of abarelix, a gonadotropin releasing hormone ( $\mathrm{GnRH})$ antagonists after subcutaneous, continuous infusion in patients with prostate cancer. Clin Pharmacol Ther 2003;73:304-11

76. Praecis Pharmaceuticals, Inc. Pharmaceutical formulations for sustained drug delivery. US5968895; 1999

77. Wong SL, Lau DT-W, Baughman SA, et al. Pharmacokinetics and pharmacodynamics of a novel depot formulation of abarelix, a gonadotropin releasing hormone $(\mathrm{GnRH})$ antagonists, in healthy men ages 50 to 75 .

J Clin Pharmacol 2004;44:495-502

78. Van Poppel H, Nilsson S. Testosteron surge: rationale for gonadotropin-releasing hormon blockers? Urology 2008;71:1001-6

79. Steiner MS, Veverka KA. Composition comprising a SARM and GnRH agonist or an GnRH antagonist, and methods of use thereof. US20060287282; 2006

- Important patent describing the combination therapy in order to avoid side effects derived from androgen decline, suppression or abrogation.

80. Felberbaum R, Diedrich K. Ovarian stimulation for in-vitro fertilization/ intracytoplasmic sperm injection with gonadotrophins and gonadotrophin-releasing hormone analogues: agonists and antagonists. Hum Reprod 1999;14:207-21

81. Meldrum DR, Scott RT, Levy MJ, et al. Oral contraceptive pretreatment in women undergoing controlled ovarian stimulation in ganirelix acetate cycles may, for a subset of patients, be associated with low serum luteinizing hormone levels, reduced ovarian response to gonadotropins and early pregnancy loss. Fertil Steril 2009;91:1963-5

82. Bellver J, Albert C, Lambarta E, Pellicer A. Early pregnancy loss in women stimulated with gonadotropin-releasing hormone antagonist protocols according to oral contraceptive pretreatment. Fertil Steril 2007;87:1098-101

83. Meldrum DR, Cassidenti DL, Rosen GF, et al. Oral contraceptive pretreatment and half dose of ganirelix does not excessively suppress LH and may be an excellent choice for scheduling IUI cycles. J Assist Reprod Genet 2008;25:417-20

84. Rivier J. GnRH analogues towards the next millenium. In: Lunenfeld B, editor, GnRH Analogues - TheState of Art at the Millenium; Parthenon Publishing: Carnforth, UK; 1999. p. 31-45

85. Haviv F, Fitzpatrick TD, Nichols CJ, et al. The effect of of NMeTyr5 substitution in luteinizing hormone-releasing hormone antagonists. J Med Chem 1993;36:928-33

86. Ferring BV. GnRH antagonists being modified in positions 5 and 6 . WO1998046634; 1998, US6214798; 2001

87. Doehn C, Sommerauer M, Jocham D. Drug evaluation: degarelix - a potential new therapy for prostate cancer. IDrugs 2006;9:565-72

88. Klotz L, Boccon-Gibod L, Shore ND, et al. The efficacy and safety of degarelix: a 12-month, comparative, randomized, open-label, parallel-group phase III study in prostate cancer patients. BJU Int 2008;102:1531-8

89. Persson B-E, Olesen TK, Jensen J-K. Degarelix: a new approach for the treatment of prostate cancer. Neuroendocrinology 2009;90:235-44

90. Doehn C, Sommerauer M, Jocham D. Degarelix and its therapeutic potential in the treatment of prostate cancer. Clin Intervent Aging 2009;4:215-23

91. Samant MP, Gulyas J, Hong DJ, et al. Iterative approach to the discovery of novel degarelix analogues: substitutions at positions 3, 7, and 8. Part II. J Med Chem 2005;48:4851-60

92. Samant MP, Gulyas J, Hong DJ, et al. Synthesis, in vivo and in vitro biological activity of novel azaline B analogs. Bioorg Med Chem Lett 2005;15:2894-7

93. AEterna Zentaris GmbH. LHRH antagonists having improved solubility properties. US7148195; 2006

-• Important patent describing new highly water soluble LH-RH antagonists such as ozarelix.

94. AEterna Zentaris GmbH. Use of LHRH antagonists for the treatment of lower urinary tract symptoms, in particular overactive bladder and/or detrusor overactivity. EP1967202; 2008

95. Pelletier JC, Chengalvala M, Cottom J, et al. 2-Phenyl-4-piprazinylbenzimidazoles: Orally active inhibitors of the gonadotropin releasing $(\mathrm{GnRH})$ receptor. Bioorg Med Chem 2008;16:6617-40

96. Heitman LH, Ijzerman AP. G protein-coupled receptors of the hypothalamic-pituitary-gonadal axis: a case for GnRH, LH, FSH, and GPR54 receptor ligands. Med Res Rev 2008;28:975-1011

-• Important summary of non-peptidic LH-RH antagonists and related patents.

97. Betz SF, Zhu YF, Chen C, Struthers RS. Non-peptide gonadotropin-releasing hormone receptor antagonists. J Med Chem 2008;51:3331-48

98. Neurocrine Biosciences, Inc. Gonadotropin-releasing hormone receptor antagonists and methods relating thereto. 
WO2005007633; 2005, US7229995;

2007

- Important patent describing elagolix and related compounds as non-peptidic LH-RH antagonists.

99. Chen C, Wu D, Guo Z, et al. Discovery of sodium R-(+)-4-\{2-[5-(2-fluoro-3methoxyphenyl)-3-(2-fluoro-6-

[trifluoromethyl] benzyl)-4-methyl-2,6dioxo-3,6-dihydro-

2H-pyrimidin-1-yl]-1-phenylethylamino\} butyrate (elagolix), a potent and orally available nonpeptide antagonist of the human gonadotropin-releasing hormone receptor. J Med Chem 2008;51:7478-85

100. Struthers RS, Nicholls AJ, Grundy J, et al. Suppression of gonadotropins and estradiol in premenopausal women by oral administration of the nonpeptide gonadotropin-releasing hormone antagonist elagolix. J Clin

Endocrinol Metab 2009;94:545-51

\author{
Affiliation \\ Gábor Mezó $^{\dagger 1}$ \& Marilena Manea ${ }^{2,3}$ \\ ${ }^{\dagger}$ Author for correspondence \\ ${ }^{1}$ Eöö?tvöö?s Loránd University, \\ Hungarian Academy of Sciences, \\ Research Group of Peptide Chemistry, \\ 1117 Budapest, \\ Pázmány P. stny. 1/A, \\ Hungary \\ Tel: +36 1209 1433; Fax: +36 1372 2620; \\ E-mail: gmezo@elte.hu \\ ${ }^{2}$ University of Konstanz, \\ Department of Chemistry, \\ Laboratory of Analytical Chemistry and \\ Biopolymer Structure Analysis, \\ 78457 Konstanz, Germany \\ ${ }^{3}$ University of Konstanz, \\ Zukunftskolleg, \\ 78457 Konstanz, \\ Germany
}

